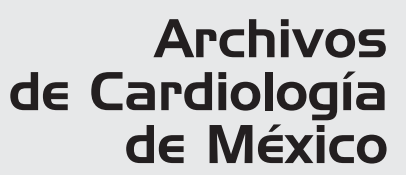

\title{
Discurso pronunciado en la ceremonia de recepción de residentes del Instituto Nacional de Cardiología Ignacio Chávez; generación 2014
}

\section{Speech delivered in the graduation ceremony of the residents of the class of $\mathbf{2 0 1 4}$ of the Instituto Nacional de Cardiología Ignacio Chávez}

\section{Sergio Trevethan Cravioto*}

\author{
Instituto Nacional de Cardiología Ignacio Chávez, México D.F., México
}

Recibido el 15 de abril de 2015; aceptado el 11 de enero de 2016

Sr. director general de esta casa, honorables miembros del presidium, excelentísimos Sres. embajadores y/o representantes de países hermanos, distinguidas personalidades que hoy nos acompañan, estimados compañeros de trabajo, Sres. médicos residentes y becarios.

Sras. y Sres.:

Hace ya 70 años que de manera ininterrumpida tiene lugar, año tras año, la ceremonia que conmemora un ciclo más de la culminación de los estudios cardiológicos y áreas afines de nuestros médicos residentes; qué decir que no haya sido mencionado ya en ocasiones anteriores, qué aportar que no sean los mismos parabienes que tradicionalmente se desean para los residentes que hoy nos abandonan y la salutación a los que ingresan.

Consciente y profundamente preocupado por el México que vivimos en la actualidad, tanto gobierno como sociedad han dejado atrás los valores de antaño de nuestro pueblo para procurar un mundo simplificado, sin más preocupación que la adquisición de los dineros necesarios para la satisfacción de las necesidades, cuando no para la procuración de frivolidades y la adquisición de logros materiales que les distingan de los que no los poseen, dejando de lado el

\footnotetext{
* Autor para correspondencia. Juan Badiano 1 Col. Sección XVI, Tlalpan CP 14080, México D.F. Teléfono: +55732911; Ext. 1134.

Correo electrónico: trevethan@cardiologia.org.mx
}

conocimiento, la honradez, el esfuerzo, el compromiso, la dignidad, la lealtad y el decoro.

Escapan en nuestro país muy pocas instituciones ya, cuya razón de ser es la de servir al hombre por el hombre mismo, no para ver qué puedo obtener de él y para pretender servirle con lo aquello que decía Don Ignacio Chávez, solo por el afán generoso de servir a los demás.

Nuestra institución es de esas.

Uds. Sres. residentes han respirado en esta casa durante 2 a 4 años esto que estoy diciendo a través de los hombres que recibimos la herencia humanística de Ignacio Chávez y de los primeros discípulos de él, y que celosamente guardamos en lo más profundo de nuestro ser.

Uds. han sido testigos de lo que afirmo ahora, a través de largas jornadas de arduo trabajo, férrea disciplina, estudio interminable y con muy poco descanso, vigilados y supervisados por todos los profesores que les han asistido en su preparación; han sido testigos también de cómo sus mismos maestros se afanan en el propio aprendizaje cotidiano, en la investigación y en la trasmisión de la enseñanza, ya sea tutorial persona a persona, en el aula o a través de las publicaciones de sus diversas investigaciones, y todo esto dentro de un ambiente de trabajo, cordialidad y ayuda recíproca.

$Y$ es que este instituto tiene tradición y prosapia que no hemos abandonado, a pesar de lo que ocurre en otros lados, o aun en el mismo instituto, en donde la indiferencia por la responsabilidad y el compromiso de algunos 
compañeros y el mismo humanismo no parece interesarles. Nosotros procuramos conservar los valores que nos fueron legados y procuramos mantenernos actualizados en la medicina moderna, la de avanzada, a pesar de lo restringido que resulta nuestro presupuesto.

En el mes de abril del año 1944 una empresa liderada por un hombre singular y de talla mayor habría de cambiar el rumbo del país en lo cardiológico; la creación de este Instituto, proveedor en muy breve tiempo de la escuela cardiológica más prestigiada tanto en México como en el resto del planeta, Institución en primera instancia dedicada a los más débiles y a los desposeídos. Un hospital sí (apuntaba Chávez), el instituto es eso, desde luego, pero también es algo más, es un lugar de remanso en donde el hombre le tiende la mano al hombre y en donde se puede dejar de ser un eco repetidor de las verdades científicas descubiertas por otros para transformar el quehacer cotidiano en fecunda investigación que se convierta en voz universal.

Me preocupa también esta nueva tendencia mundial, dictada por la medicina anglosajona, y a mi juicio carente de raciocinio y sentido común, pero que ha invadido nuestra esfera y parece subyugar a los jóvenes, plagada de guías, algoritmos y demás recetas de cocina que convierten el quehacer del médico en dogmas basados exclusivamente en respuestas provenientes del laboratorio o del gabinete, y deja de lado el análisis juicioso del clínico. En el buen estudio clínico está la base de todo diagnóstico, no hay métodos instrumentales que puedan sustituirlo, lo que ellos hacen maravillosamente es completarlo, depurarlo, afinarlo. Sentenciaba Chávez: «Habrá siempre lugar para que el clínico diga su palabra y conduzca la medicina del futuro como la ha conducido hasta hoy».

Tal afirmación continúa siendo cierta, a pesar del enorme despliegue tecnológico, la sobrepoblación, la voracidad por el lucro, o en ocasiones lo que resulta más preocupante, la real necesidad por los dineros y el deseo por la simplificación en el quehacer, que están obligando a las nuevas generaciones a lo contrario. Es por esto que les exhorto para que no abandonen nunca la medicina clínica, así la tengan que ejercer al lado del tomógrafo, en una sala de hemodinámica o de electrofisiología, de ecocardiografía, de gamagrafía o de resonancia magnética nuclear.

La calidad de la medicina se mide por el acierto y la profundidad del diagnóstico, pero ese desideratum reclama para ser alcanzado de la correcta exploración del paciente. Poder explorar - decía Chávez también-, reza el aforismo hipocrático, es gran parte del arte; esa sentencia entraña un mandato que no debe olvidar quien quiera adentrarse en la cardiología.

Es necesario también que recuerden que el saber de hoy es verdad provisional, siempre sujeta a revisión. Es por eso que cuando estudiando cualquier tema algún alumno me pregunta qué hace Ud. profesor, tengo que responder aprendiéndome hoy la mentira del mañana. Si no, valga como ejemplo esta aseveración que se hacía en 1970 cuando yo era residente en todos los libros de texto de hemodinamia: en las contraindicaciones precisas para meter a un paciente en la sala de cateterismo la principal era el infarto agudo de miocardio, cuando hoy es la razón primera para hacerlo.

Recuerden Uds. también que profesores los somos todos, unos buenos, unos regulares y otros malos, pero que el ser maestro es privilegio solo de unos cuantos. Dominen la cátedra, que es la mejor manera de seguir aprendiendo, perfeccionen la técnica, no atropellen sus palabras, ni mucho menos sus ideas. Compartan el saber cómo lo harían con sus hijos y tributen a sus maestros el mismo respeto que a los autores de sus días, como nos lo manda Hipócrates.

Cierto es que el México de nuestro tiempo es muy diferente al México de los tiempos del maestro Chávez en los días de gloria de nuestra institución, y que los logros de Chávez fueron catalogados por él mismo como producto del hombre y de su circunstancia, de acuerdo con la concepción de Ortega y Gasset vislumbrada ya desde 1914 en sus Meditaciones del Quijote. En este contexto algo de razón tenía el maestro en atribuir sus logros a su circunstancia, pero yo debo agregar... ¡cuántos hombres hemos conocido a los cuales la circunstancia, el entorno, la naturaleza o lo que fuese les proveyó de grandes oportunidades que exclusivamente aprovecharon para el engrandecimiento de su propio peculio! Pero también cuántos hombres emplean su circunstancia y la adecuan para provecho de sus semejantes.

Chávez dejo plasmado con el pincel de Diego, en los hermosos frescos que se encuentran en el vestíbulo de este auditorio, la historia de la cardiología, desde los tiempos de Galeno de Pérgamo hasta la fundación de este Instituto. Más de 2,000 años de historia. Si hogaño nos fuese dado volver a pintar esta historia, desde ese entonces a la fecha, no alcanzarían todos los muros del perímetro del instituto para contar lo ocurrido en tan solo los últimos 71 años. El escrito de Chávez acerca de estos frescos termina con estas hermosas frases.

«Es la evocación del pasado heroico con su gran lección de humildad, la voz de los maestros de ayer que guarda vivo su poder de estímulo, una tradición amasada en siglos que nos ordena continuarla.

La juventud que pase por las aulas habrá de familiarizarse con estas grandes figuras del pensamiento y al conocerlas habrá de cultivar la santa actitud de la veneración».

A los residentes de nuevo ingreso les invito a trabajar arduamente, como lo hacemos muchos de nosotros; los de la edad avanzada, pero con el conocimiento y el corazón por delante, los invito a dejar hábitos cómodos y el trabajo sencillo y simplificado, a no conformarse con lo que ahora se da por hecho, los invito, en una palabra, a hacer suyo nuestro método y nuestros anhelos.

La gran mayoría de los mandos medios y superiores de esta institución somos chavistas, empezando por nuestro director general, quien cuida y mantiene con celo la herencia, al igual que la mayoría de nosotros. "Cuántas vidas más podrá tener este instituto» - se preguntaba Don Ignacio en la inauguración de estas nuevas instalaciones hace ya 40 años - y su respuesta inmediata era: «Las que sus hijos, los de las generaciones próximas, sean capaces de forjarle con su esfuerzo, por eso en esta solemne ceremonia quise dejar impreso en sus corazones y sus conciencias el ejemplo claro del camino que hay que recorrer por delante, que en vez de terminar aquí, por el contrario, es apenas ahora cuando empieza, con una vida limpia, honesta, leal y agradecida con el alma mater y su país; pero desde luego en aras del hombre enfermo como principio único, como nos enseñó el maestro». 
Ignacio Chávez Sánchez partió físicamente hace ya 36 años, en alguna ocasión se puede escuchar por ahí a algún joven estudiante preguntando de quién es ese busto, o qué es lo que hizo ese señor, y muy probablemente de facto desconozca la obra de Chávez, pero nosotros en el instituto estamos seguros de que lo que pregunta ese joven acerca de quién fue ese personaje, lo está respirando y asimilando por sus poros día tras día en el ambiente que lo rodea, mientras completa su entrenamiento, de la misma manera que lo han respirado Uds. como residentes en esta casa.

Nosotros mismos no estamos ciertos de que en verdad haya muerto el maestro. Esa mística de vida no desaparece nunca, se pasa de maestros a discípulos como la mística del abuelo al padre y la del padre al hijo.
Enhorabuena. Muchas gracias.

Sergio Trevethan Cravioto. Subdirector de enseñanza. 27 de febrero de 2015.

\section{Financiación}

No se recibió patrocinio de ningún tipo para llevar a cabo este artículo.

\section{Conflicto de intereses}

El autor declara no tener ningún conflicto de intereses. 